\title{
The von Willebrand factor A-1 domain binding aptamer BT200 elevates plasma levels of von Willebrand factor and factor VIII: a first-in-human trial
}

Katarina D. Kovacevic, Jürgen Grafeneder, Christian Schörgenhofer, Georg Gelbenegger, Gloria Gager, Christa Firbas, ${ }^{1}$ Peter Quehenberger, ${ }^{2}$ Petra Jilma-Stohlawetz, ${ }^{2}$ Andrea Bileck, ${ }^{3}$ Shuhao Zhu, ${ }^{4}$ James C. Gilbert, ${ }^{4}$ Martin Beliveau, ${ }^{5}$ Bernd Jilma ${ }^{1}$ and Ulla Derhaschnig ${ }^{1}$

'Department of Clinical Pharmacology, Medical University of Vienna, Vienna, Austria; ${ }^{2}$ Clinical Institute of Laboratory Medicine, Medical University of Vienna, Vienna, Austria; ${ }^{3}$ Joint Metabolome Facility, University of Vienna \& Medical University of Vienna, Vienna, Austria, ${ }^{4}$ Guardian Therapeutics Inc., Lexington, KY, USA and ${ }^{5}$ Certara, Montreal, Quebec, Canada
Correspondence: K. Kovacevic katarina.kovacevic@meduniwien.ac.at

Received: September 6, 2021 Accepted: $\quad$ October 21, 2021. Prepublished: November 25, 2021. https://doi.org/10.3324/haematol.2021.279948

@2022 Ferrata Storti Foundation Published under a CC BY-NC license @(])

\begin{abstract}
von Willebrand factor (VWF) and factor VIII (FVIII) circulate in a noncovalent complex in blood and promote primary hemostasis and clotting, respectively. A new VWF A1-domain binding aptamer, BT200, demonstrated good subcutaneous bioavailability and a long half-life in non-human primates. This first-in-human, randomized, placebo-controlled, doubleblind trial tested the hypothesis that BT200 is well tolerated and has favorable pharmacokinetic and pharmacodynamic effects in 112 volunteers. Participants received one of the following: a single ascending dose of BT200 (0.18-48 mg) subcutaneously, an intravenous dose, BT200 with concomitant desmopressin or multiple doses. Pharmacokinetics were characterized, and the pharmacodynamic effects were measured by VWF levels, FVIII clotting activity, ristocetin-induced aggregation, platelet function under high shear rates, and thrombin generation. The mean half-lives ranged from 7-12 days and subcutaneous bioavailability increased dose-dependently exceeding 55\% for doses of 6-48 mg. By blocking free A1 domains, BT200 dose-dependently decreased ristocetin-induced aggregation, and prolonged collagen-adenosine diphosphate and shear-induced platelet plug formation times. However, BT200 also increased VWF antigen and FVIII levels 4-fold $(P<0.001)$, without increasing VWF propeptide levels, indicating decreased VWF/FVIII clearance. This, in turn, increased thrombin generation and accelerated clotting. Desmopressin-induced VWF/FVIII release had additive effects on a background of BT200. Tolerability and safety were generally good, but exaggerated pharmacology was seen at saturating doses. This trial identified a novel mechanism of action for BT200: BT200 dose-dependently increases VWF/FVIII by prolonging half-life at doses well below those which inhibit VWF-mediated platelet function. This novel property can be exploited therapeutically to enhance hemostasis in congenital bleeding disorders.
\end{abstract}

\section{Introduction}

von Willebrand factor (VWF) and factor VIII (FVIII) circulate in a noncovalent complex in blood and promote primary hemostasis and clotting, respectively. ${ }^{1}$ VWF plays a dual role in hemostasis: firstly, it is crucial for platelet adhesion as it bridges glycoprotein Gplb on platelets via the A1 domain to collagen localized in the subendothelial matrix of damaged vessels, ${ }^{2}$ secondly it reduces the clearance of coagulation FVIII. ${ }^{3}$ Deficiency of VWF (Willebrand disease or syndrome) causes primarily mucocutaneous bleeding, ${ }^{4,5}$ and deficiency of FVIII (hemophilia A) leads to joint and muscle bleeding. Both of these disorders can result in disastrous bleeding during surgery or after trauma, and necessitate substitution of VWF or FVIII, or non-factor replacement therapy in severe cases. ${ }^{6}$

Only recently, VWF has become a target for therapeutic interventions in prothrombotic diseases. As VWF mediates thrombus formation under high shear rates, therapeutic inhibition of VWF is a potential target for cardiovascular diseases. ${ }^{7-9}$ Proof of this concept was first established by demonstrating: (i) that inhibition of the VWF A1-domains reduced the number of microembolic signals during carotid endarterectomy; ${ }^{10}$ and (ii) that it improved thrombocytopenia in thrombotic thrombocytopenic purpura, ${ }^{11}$ a condition caused by a congenital or acquired deficiency of the VWF cleaving enzyme (ADAMTS-13). ${ }^{12}$ This led to small ${ }^{13,14}$ and larger clinical trials, ${ }^{15-17}$ which eventually led to the success- 
ful testing of the anti-VWF nanobody caplacizumab in phase II/III trials and its subsequent marketing authorization for acquired thrombotic thrombocytopenic purpura. Aptamer-mediated blockade of VWF A1-domains was also demonstrated to be effective in patients with a gain-offunction VWF mutation (type $2 \mathrm{~B}$ von Willebrand disease [VWD]), increasing both VWF and FVIII plasma levels, as well as platelet counts. ${ }^{18,19}$ These pro-hemostatic actions might also be exploited therapeutically. Previous generations of anti-VWF aptamers, for example aptamer ARC1779, had a suboptimal short half-life ${ }^{11,20}$ or suboptimal stability at higher temperatures. For those reason we designed a next-generation VWF-A1-binding aptamer, BT200, which recently showed good subcutaneous bioavailability ( $\geq 77 \%)$ and a long half-life in non-human primates $\left(>100\right.$ h). ${ }^{21}$ This first-in-human, randomized, double-blind, placebo-controlled trial set out to test the hypothesis that BT200 is well tolerated, safe and has favorable pharmacokinetics and pharmacodynamic effects.

\section{Methods}

This trial was approved by the national competent authority (BASG) and the Ethics Committee of the Medical University of Vienna. The study protocol, subsequent amendments, and informed consent were written according to the Declaration of Helsinki and the trial was conducted according to the International Council on Harmonization guidelines for Good Clinical Practice, which was monitored by an external contract research organization. Patients provided written informed consent prior to their participation in the trial. This trial was registered under EUDRA-CT\# 2019-001818-42 and NCT04103034 at www.clinicaltrials.gov. This was a single-center trial and all authors had open access to the primary clinical data. Upon a justified request, the principal investigator will grant access to the primary clinical trial data.

This trial used a 3:1 randomized, double-blind, placebocontrolled integrated protocol design with 14 dose cohorts. Each cohort comprised six subjects receiving active treatment and two receiving placebo. Placebotreated volunteers were pooled within each part of the study and analyzed together. Randomization was done centrally using an electronic system provided by Assign Data Management and Biostatistics (Innsbruck, Austria). Part A of the study was a single ascending dose study, part $B$ a multiple ascending dose study, part $D$ an intravenous (IV) bioavailability study (IV infusion over $24 \mathrm{~h}$ ) and part $C$ was a drug-drug interaction study with the VWF secretagogue, desmopressin, given as a single dose $(0.3 \mu \mathrm{g} / \mathrm{kg}$ IV over $30 \mathrm{~min})$ approximately $96 \mathrm{~h}$ after administration of $48 \mathrm{mg} \mathrm{BT200} \mathrm{(i.e.,} \mathrm{at} \mathrm{approximately} \mathrm{the}$ $t_{\max }$ of BT200). Healthy male or female subjects of non- childbearing potential were invited to participate. Because reproductive toxicology studies do not exist at this point, the relevant regulatory agency recommended excluding women of childbearing potential at this early stage of development. After written informed consent and passing a screening examination subjects received single doses of BT200 ranging from 0.18 to $24 \mathrm{mg}$ via subcutaneous (SC) injection (cohorts 1-7), SC infusion (drug diluted in $100 \mathrm{~mL} \mathrm{NaCl}$ ) of 24,36 and $48 \mathrm{mg}$ over $1 \mathrm{~h}$ (cohorts 8-10) or a 24-hour IV infusion of $24 \mathrm{mg}$ (cohort 11) (Table 1). Subjects were confined to bed rest for the first hour; oxygen saturation and heart rate were monitored, and blood pressure was measured repeatedly. Subjects in the multiple-dose cohorts received a split loading dose (IV over $2 \mathrm{~h} / \mathrm{SC}$ ) of $12 / 12 \mathrm{mg}$ or $24 / 24 \mathrm{mg}$. In cohort 13 this was followed by weekly SC injections of $12 \mathrm{mg}$ until day 28.

BT200 is a fully 2'-O-methylated RNA aptamer ${ }^{21}$ conjugated to a $40 \mathrm{kD}$ polyethylene glycol, and it was supplied at a concentration of $15 \mathrm{mg} / \mathrm{mL}$ in sterile saline for injection (all doses refer to the unconjugated aptamer). A sterile saline solution $(0.9 \mathrm{NaCl})$ was used as placebo

Table 1. Enrolled study population and treatment.

\begin{tabular}{|c|c|c|c|}
\hline $\begin{array}{l}\text { Study } \\
\text { Part }\end{array}$ & Cohort & Treatment & $\mathbf{N}$ \\
\hline A & 1 & $0.18 \mathrm{mg} \mathrm{BT200/placebo} \mathrm{-} \mathrm{SC} \mathrm{injection}$ & 8 \\
\hline A & 2 & $0.6 \mathrm{mg} \mathrm{BT200/placebo} \mathrm{-} \mathrm{SC} \mathrm{injection}$ & 8 \\
\hline A & 3 & $1.8 \mathrm{mg} \mathrm{BT200/placebo} \mathrm{-} \mathrm{SC} \mathrm{injection}$ & 8 \\
\hline A & 4 & 6 mg BT200/placebo - SC injection & 8 \\
\hline A & 5 & 12 mg BT200/placebo - SC injection & 8 \\
\hline A & 6 & 18 mg BT200/placebo - SC injection & 8 \\
\hline A & 7 & 24 mg BT200/placebo - SC injection & 8 \\
\hline A & 8 & 24 mg BT200/placebo - SC infusion & 8 \\
\hline A & 9 & 36 mg BT200/placebo - SC infusion & 8 \\
\hline A & 10 & 48 mg BT200/placebo - SC infusion & 8 \\
\hline D & 11 & 24 mg BT200/placebo - IV infusion & 8 \\
\hline C & 12 & $\begin{array}{l}48 \mathrm{mg} \mathrm{BT} 200 / \text { placebo - SC injection with } \\
\text { desmopressin challenge }\end{array}$ & 8 \\
\hline B & 13 & $\begin{array}{l}24 \mathrm{mg} \mathrm{BT200/placebo} \mathrm{-} \mathrm{IV} \mathrm{infusion} \mathrm{with} \\
12 \mathrm{mg} \mathrm{SC} \text { injection, followed by } 4 \text { weekly } \\
\text { doses of } 12 \mathrm{mg}\end{array}$ & 8 \\
\hline B & 14 & $\begin{array}{l}24 \text { mg BT200/placebo - IV infusion with } \\
24 \text { mg SC injection }\end{array}$ & 8 \\
\hline
\end{tabular}

In each cohort six volunteers were randomized to BT200 and two to placebo. N: number of subjects; SC: subcutaneous; IV: intravenous. 
and desmopressin was supplied as a commercially available sterile solution for injection in $4.0 \mu \mathrm{g} / \mathrm{mL}$ ampoules (Octostim, Ferring, Austria).

A description of analytical methods and the statistical analysis is provided in the Online Supplementary Data.

\section{Results}

Randomization of 112 subjects was planned; due to slower recruitment during the COVID pandemic, 20 subjects from part A were re-exposed (once) in part B, C or D. Thus, a total of 92 individual subjects were enrolled in 14 cohorts.

\section{Single subcutaneous doses and intravenous bioavailability study}

In part A, 86 subjects were screened, 60 were randomized to BT200 and 20 to placebo. Cohort 9 included one early termination and cohort 10 two early terminations due to COVID-19. Two volunteers were Asian, one African, and the rest Caucasian. The male:female sex ratio of participants was $72: 8$, and their age ranged from 18 to 60 years. Complete demographic characteristics are given in Online Supplementary Table S1.

In part $D$, eight subjects from part A (including 1 woman and the 2 Asian volunteers) were re-exposed and they received intravenous doses of placebo or BT200; their mean age was 31.3 years (Online Supplementary Table S2).

\section{Pharmacokinetics}

The rate and extent of exposure to BT200 increased with increasing doses over the dose range of $0.18 \mathrm{mg}$ to $24 \mathrm{mg}$ after single SC injections (Figure 1). The increase over the dose range for areas under the concentration curve (AUC) and maximum concentration $\left(\mathrm{C}_{\max }\right)$ appeared to be proportional to dose for dose levels $\geq 6 \mathrm{mg}$. For SC infusions, the rate and extent of exposure to BT200 also increased in a dose-proportional manner. Geometric mean halflives $\left(t_{1 / 2}\right)$ ranged from 121 to $279 \mathrm{~h}$ (Table 2). Clearance $(\mathrm{CL} / \mathrm{F})$ decreased as a function of body weight and age. The half-life was $204 \mathrm{~h}$ after a $24 \mathrm{~h}$ IV infusion and the $\mathrm{C}_{\max }$ reached $4.8 \mu \mathrm{g} / \mathrm{mL}$, the geometric mean clearance $(\mathrm{CL})$ was $0.0264 \mathrm{~L} / \mathrm{h}$ and the volume of distribution $\left(\mathrm{V}_{\mathrm{ss}}\right)$ was $4.54 \mathrm{~L}$. Therefore, as had been expected, clearance was much lower than glomerular filtration rate $(7.5 \mathrm{~L} / \mathrm{h})$. The volume of distribution was consistent with the blood volume of human volunteers ( $5 \mathrm{~L})$, and similar to that seen for other pegylated aptamers ${ }^{22}$ which are not primarily eliminated via passive renal filtration.

The bioavailability of BT200 was approximately $64 \%$ following SC injection and $75 \%$ following SC infusion. Bioavailability was lower for doses below $1.8 \mathrm{mg}$ (33 to 50\%), as expected from the dose proportionality analysis.

\section{Multiple ascending dose cohorts (cohorts 13, 14)}

In part B, 16 subjects ( 14 men and 2 women )were included (8 of whom were re-exposed from part A). One subject was Asian and the rest were Caucasian. The mean age was 43 years (standard deviation [SD] 13), mean height was $180 \mathrm{~cm}$ (SD 11), mean weight was $87 \mathrm{~kg}$ (SD 17) and the mean body mass index was $26.8 \mathrm{~kg} / \mathrm{m}^{2}$ (SD 4.5) (Online Supplementary Table S3).

\section{Pharmacokinetics}

As expected, the combination of IV infusions over $2 \mathrm{~h}$ and SC injections in a split SC/IV loading dose resulted in peak levels being observed much earlier than was seen after the same dose was administered via the SC route alone (Figure 1). The exposure ( $A \cup C$ and $C_{\max }$ ) was only slightly higher that that of an equivalent injected or SC infused dose in part A. Mean trough concentrations of BT200 appeared to plateau by day 7 and remained consistent through to day 28 following weekly maintenance doses of 12 mg BT200 (Online Supplementary Figure S1). Subjects in cohort 14 received only the initial dose but not any of the subsequent maintenance doses, because the maximum tolerated dose had been reached and the aims of the trial fulfilled.

\section{Pharmacodynamic effects in all cohorts}

BT200 concentration-dependently inhibited VWF-dependent platelet function (Online Supplementary Figures S2 and S3): a $12 \mathrm{mg}$ dose was necessary to fully prolong collagen-ADP closure times as measured by the Platelet Function Analyzer (PFA) (Online Supplementary Figures S4 and S5) to a median of $300 \mathrm{~s}$ (range: $148-300 \mathrm{~s} ; P<0.001$ ) $48 \mathrm{~h}$ after sc injection, which coincided with the nadir of free VWF A1-domains in this cohort (Figure 2). Maximal PFA closure prolongation was short lived and did not persist even until the maximal plasma concentration of 1.2 $\mu \mathrm{g} / \mathrm{mL}$ was observed at $72 \mathrm{~h}$ following the $12 \mathrm{mg}$ dose. Likewise, ristocetin-induced platelet aggregation decreased from $92 \mathrm{U}$ (range, 69-117 $\mathrm{U}$ ) to a nadir of $34 \mathrm{U}$ (range, 13-58 U; $P<0.001)$ after $96 \mathrm{~h}$ (Online Supplementary Figures $\mathrm{S} 5$ and $\mathrm{S6}$ ).

All three lower SC doses of BT200 had a minimal effect on free VWF A1-domains which was comparable to that observed for placebo (Figure 2). The $6 \mathrm{mg}$ dose moderately suppressed free VWF A1-domains by $30 \%(P<0.001)$. Doses of 12-48 mg invariably decreased free VWF A1-domains to $<50 \%$ of normal values, although the extent of decrease appeared to be more pronounced in subjects with low baseline levels of VWF. The $48 \mathrm{mg}$ dose reduced median free VWF A1-domains to $2 \%$ (range, 2-6\%) at $48 \mathrm{~h}$, and the 24-h IV infusion of $24 \mathrm{mg}$ BT200 quickly reduced free VWF A1-domains to $1 \%$ (range, $0-7 \%$ ). At equivalent exposure, the IV infusion yielded a greater extent of suppression compared to the SC injection, consistent with 
A

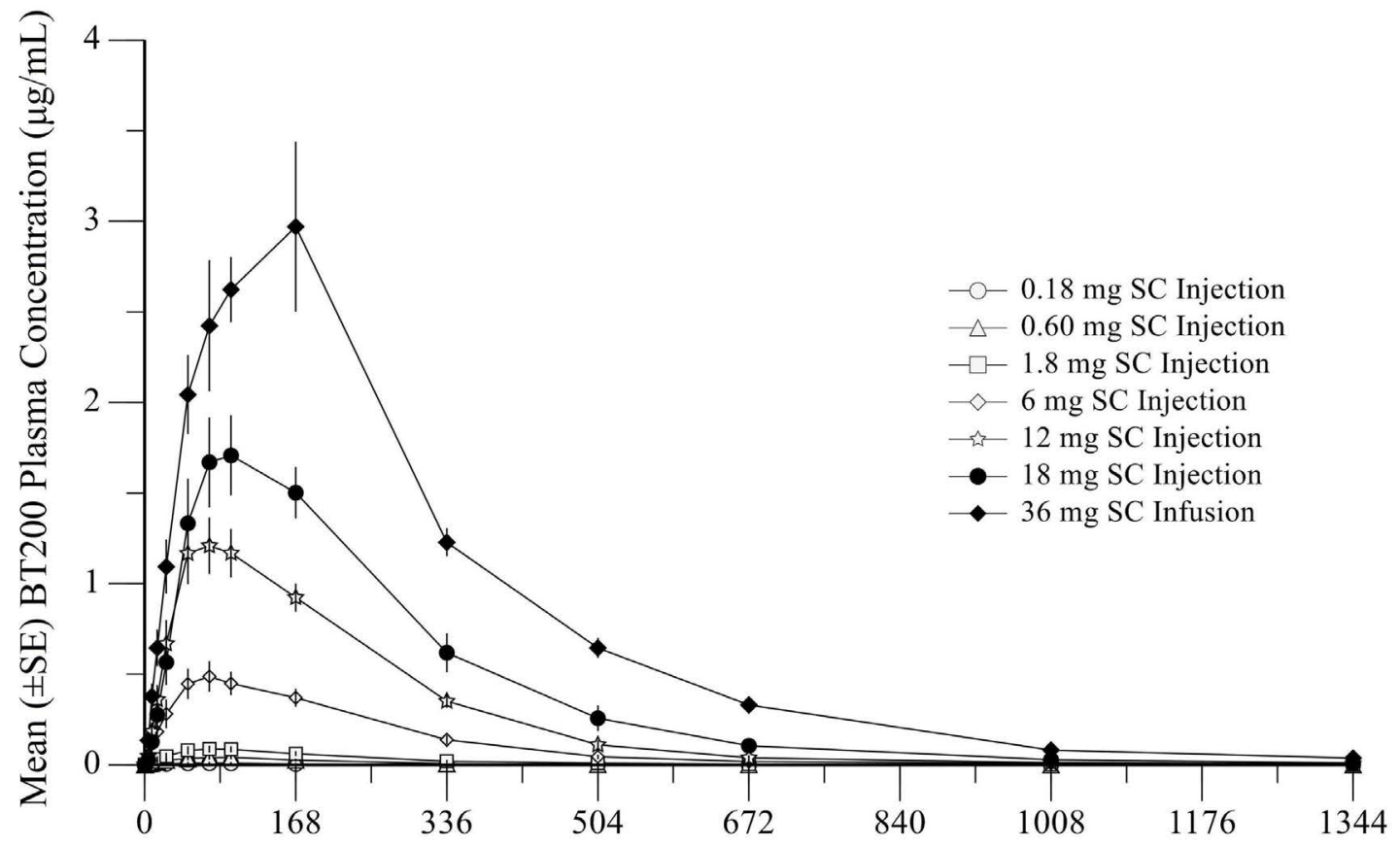

B

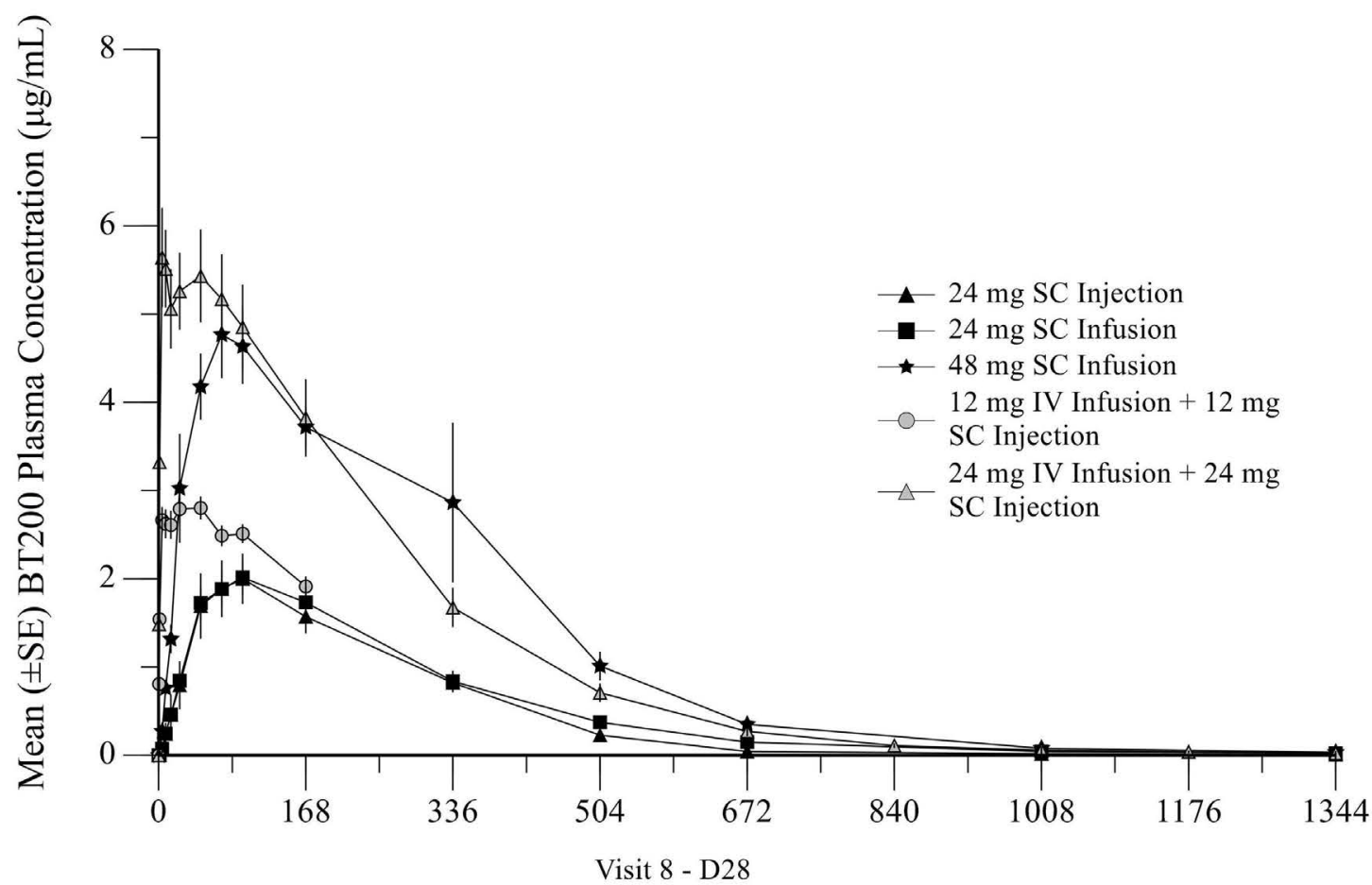

C

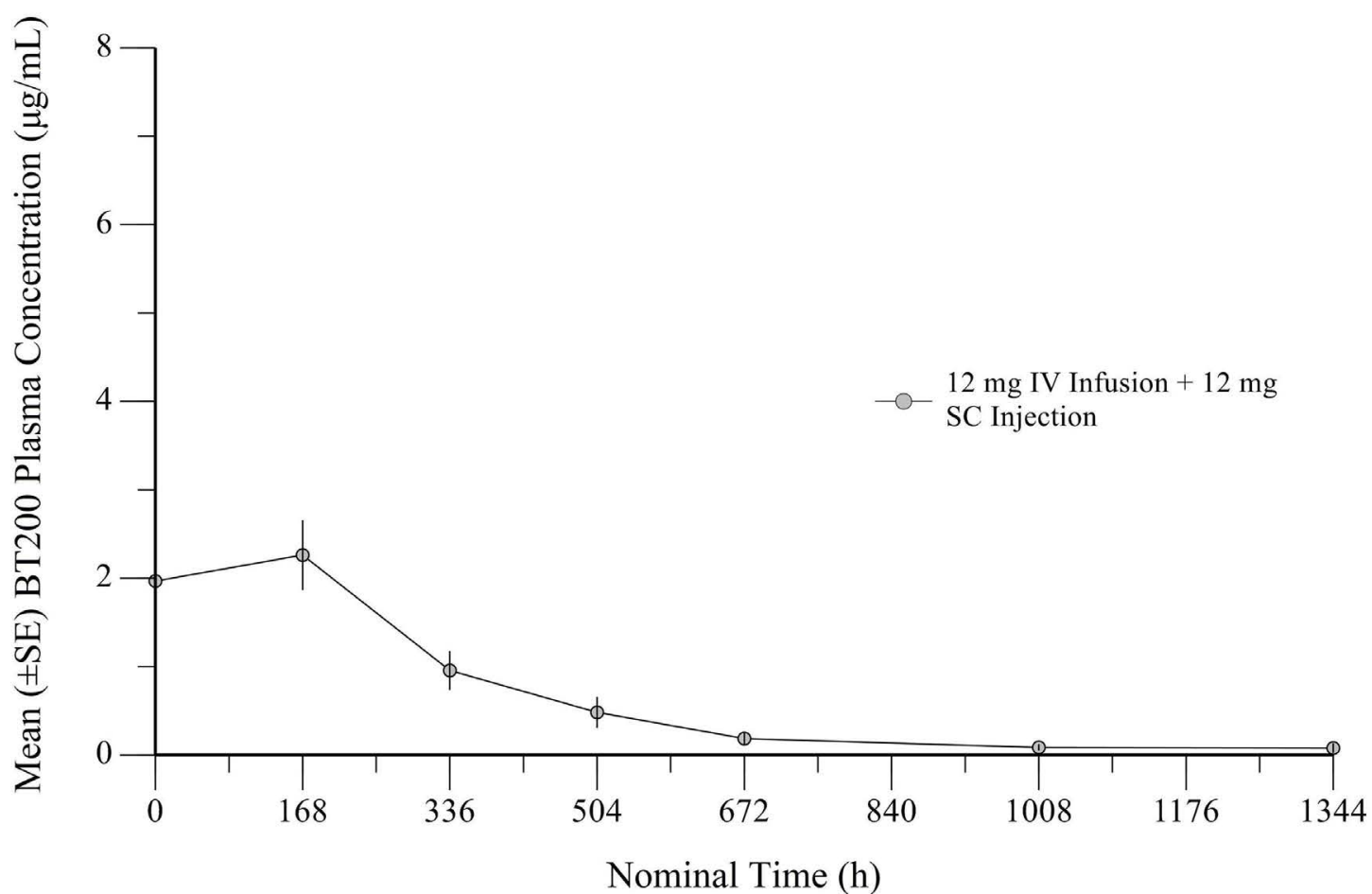

Figure 1. Plasma concentration versus time profiles of the anti-von Willebrand factor aptamer, BT200, in healthy volunteers. Mean (with standard error) plasma levels of BT200 over time after: (A) single subcutaneous injections or infusions in healthy volunteers $(n=6)$; (B) single subcutaneous injections or infusions in healthy volunteers $(n=6)$; $(C)$ the last of five subcutaneous doses in healthy volunteers (part B of the study) $(n=6)$. SE: standard error; SC: subcutaneous; IV: intravenous; D28: day 28. 
the different kinetic profiles observed following IV or SC administration.

The effect of BT200 on VWF:RCo appeared to be less pronounced when compared to that on free VWF A1-domains. For example, the $36 \mathrm{mg}$ dose reduced median VWF:RCo from $108 \%$ to $30 \%$ (Online Supplementary Figure S7), but median free VWF A1-domains from $84 \%$ to $6 \%$ after $48 \mathrm{~h}$ (both $P<0.001$; Friedman ANOVA). This apparent discrepancy reflects the 2-fold increase in circulating VWF antigen levels after $48 \mathrm{~h}$, and because VWF:RCo is sensitive to changes in VWF levels, the effects of BT200 were less pronounced in VWF:RCo when compared to the free VWF A1-domains. Circulating VWF antigen mass increased as early as $24 \mathrm{~h}$ after the start of the IV infusion, and reached levels 4-fold higher than baseline between 7-14 days after SC doses of 24-48 mg $(P<0.001)$ (Figure 3). VWF antigen levels increased 4-fold following multiple SC maintenance doses of $12 \mathrm{mg}$ BT200 $(P<0.001)$ (Figure 4).

As VWF is the carrier for FVIII, there was a corresponding 3- to 4-fold increase in FVIII activity levels 7 days after SC administration of $24-48 \mathrm{mg}$ BT200 $(P<0.001)$ (Figure $5)$. Multivariate analysis showed that the FVIII levels not only correlated with the dose, but also with baseline VWF antigen levels (multiple $r^{2}$ values ranging from $0.66-$ 0.78 from $48 \mathrm{~h}$ to 21 days; $P<0.001$ ). Whereas a minimal increase of FVIII activity was observed following SC injection of BT200 at lower dose levels $(0.18,0.6,1.8 \mathrm{mg})$,

Table 2. Plasma BT200 pharmacokinetic parameters following a single administration of BT200 to normal human volunteers (parts $A$ and $B$ ).

Plasma pharmacokinetic parameters ${ }^{\mathrm{a}}$

\begin{tabular}{|c|c|c|c|c|c|c|}
\hline $\begin{array}{l}\text { Dose in } \\
\mathrm{mg}(\mathrm{N})\end{array}$ & $\begin{array}{c}\text { AUC }_{0-168} \\
\left(h^{*} \mu \mathrm{g} / \mathrm{mL}\right)\end{array}$ & $\begin{array}{c}\text { AUC }_{0-\infty}{ }^{d} \\
(h * \mu g / m L)\end{array}$ & $\begin{array}{c}C_{\max } \\
(\mu g / m L)\end{array}$ & $t_{\max }^{b}(h)$ & $t_{1 / 2}(h)$ & $C L^{f}(L / h)$ \\
\hline
\end{tabular}

\section{Part A (SC injection)}

\begin{tabular}{|c|c|c|c|c|c|c|c|}
\hline $0.18(6)$ & $0.968(75.4) ; 6$ & $3.42(21.5) ; 3^{c, d}$ & $\begin{array}{c}0.00903 \\
(60.3) ; 6\end{array}$ & $\begin{array}{c}71.93(46.83 ; \\
336.90) ; 6\end{array}$ & $149(11.8) ; 3^{c, d}$ & $0.0526(21.5) ; 3^{c, d}$ & $12.4(22.9) ; 3^{c, d}$ \\
\hline $0.6(6)$ & $5.02(45.8) ; 6$ & $8.06(41.5) ; 5^{c}$ & $0.0431(50.4) ; 6$ & $\begin{array}{c}83.64(47.58 ; \\
97.95) ; 6\end{array}$ & $121(55.8) ; 5^{c}$ & $0.0744(41.5) ; 5^{c}$ & $14.1(50.4) ; 5^{c}$ \\
\hline $1.8(6)$ & $10.7(43.4) ; 6$ & $22.3(31.0) ; 6$ & $0.0890(37.9) ; 6$ & $\begin{array}{c}71.68(47.90 ; \\
97.43) ; 6\end{array}$ & $239(55.2) ; 6$ & $0.0807(31.0) ; 6$ & $21.9(58.4) ; 6$ \\
\hline $6(6)$ & $60.5(42.6) ; 6$ & $127(24.6) ; 6$ & $0.475(45.0) ; 6$ & $\begin{array}{c}72.86(48.28 ; \\
168.98) ; 6\end{array}$ & $279(22.2) ; 6$ & $0.0471(24.6) ; 6$ & $11.3(41.8) ; 6$ \\
\hline $12(6)$ & $157(25.6) ; 6$ & $315(21.9) ; 6$ & $1.22(25.0) ; 6$ & $\begin{array}{c}73.24(48.20 ; \\
97.45) ; 6\end{array}$ & $263(26.5) ; 6$ & $0.0381(21.9) ; 6$ & $8.71(28.1) ; 6$ \\
\hline $18(5)^{\mathrm{e}}$ & $213(29.5) ; 5$ & $499(29.7) ; 5$ & $1.69(28.7) ; 5$ & $\begin{array}{c}94.93(72.07 ; \\
97.50) ; 5\end{array}$ & $204(25.5) ; 5$ & $0.0361(29.7) ; 5$ & $9.32(29.9) ; 5$ \\
\hline $24(6)$ & $235(59.9) ; 6$ & $550(42.7) ; 6$ & $1.92(54.0) ; 6$ & $\begin{array}{c}95.72(48.58 ; \\
168.62) ; 6\end{array}$ & $184(27.4) ; 6$ & $0.0436(42.7) ; 6$ & $10.4(60.0) ; 6$ \\
\hline
\end{tabular}

\section{Part A (SC infusion)}

\begin{tabular}{|c|c|c|c|c|c|c|c|}
\hline $24(6)$ & $260(23.2) ; 6$ & $646(19.8) ; 6$ & $2.03(24.0) ; 6$ & $\begin{array}{c}96.10(48.22 ; \\
98.00) ; 6\end{array}$ & $240(41.8) ; 6$ & $0.0371(19.8) ; 6$ & $10.6(25.9) ; 6$ \\
\hline $36(6)$ & $359(22.0) ; 6$ & $1007(12.1) ; 6$ & $3.09(34.3) ; 6$ & $\begin{array}{c}166.77(72.83 ; \\
168.73) ; 6\end{array}$ & $203(6.53) ; 6$ & $0.0358(12.1) ; 6$ & $10.9(20.1) ; 6$ \\
\hline $48(6)$ & $633(14.8) ; 6$ & $1507(14.5) ; 4$ & $5.46(16.2) ; 6$ & $\begin{array}{c}71.86(24.50 ; \\
336.23) ; 6\end{array}$ & $193(17.0) ; 4$ & $0.0319(14.5) ; 4$ & $8.44(5.66) ; 4$ \\
\hline
\end{tabular}

\section{Part B}

\begin{tabular}{|c|c|c|c|c|c|c|c|}
\hline $24(6)$ & $408(7.81) ; 6$ & NC & $3.00(8.61) ; 6$ & $\begin{array}{c}23.69(4.00 ; \\
71.82) ; 6\end{array}$ & NC & NC & NC \\
\hline $48(6)$ & $787(25.4) ; 6$ & $1527(28.5) ; 6$ & $5.69(24.7) ; 6$ & $\begin{array}{c}5.77(4.00 ; \\
49.33) ; 6\end{array}$ & $243(17.7) ; 6$ & $0.0314(28.5) ; 6$ & $6.99(24.4) ; 6$ \\
\hline
\end{tabular}

${ }^{a}$ Data are presented as geometric means with geometric coefficients of variation (GeoCV\%); n. of subjects. ${ }^{b}$ Median (minimum, maximum); $n$. of subjects. ${ }^{\mathrm{C}} \mathrm{AUC} \mathrm{C}_{0-\infty}$ and all $\lambda_{\mathrm{z}}$-related pharmacokinetic parameters were not calculated for concentration-time profiles that did not have a well-characterized terminal phase. ${ }^{\mathrm{d} T h e} \mathrm{AUC}_{0-\infty}$ values were extrapolated by more than $20 \%$ for one subject in cohort 1 , the $A \cup C_{0-\infty}$ and all

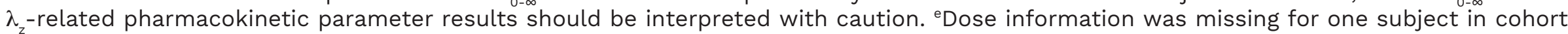
6: the pharmacokinetic results for this subject were excluded from the summary statistics. 'Following extravascular administration (subcutaneous), this parameter is expressed over $\mathrm{F}$ (i.e., $\mathrm{CL} / \mathrm{F}$ and $\mathrm{V}_{\mathrm{ss}} / \mathrm{F}$ ). AUC: area under the concentration-time curve; $\mathrm{C}_{\mathrm{max}}$ : maximum concentration; tmax: time at which peak concentration occurs; $\mathrm{t}_{1 / 2}$ : half-life, CL: clearance; Vss: apparent volume of distribution at steady state; NC: not calculated; $\lambda_{z}$ : terminal rate constant; F: absolute bioavailability. 
doubling of FVIII was already seen in some individuals after a single $6 \mathrm{mg}$ dose. Increased FVIII levels were reflected by a reciprocal shortening of the activated partial thromboplastin time $(P<0.001)$ (Online Supplementary Figure $S 8$ ), and an up to 2-fold increase in peak thrombin generation $(P<0.001)$ (Online Supplementary Figure S9). To investigate the potential mechanism of action for the increased VWF/FVIII levels, we considered that increased VWF secretion might contribute to the VWF elevation and therefore measured VWF propeptide levels. However, BT200 did not raise VWF propeptide levels (Online Supplementary Figure S10), resulting in a 4-fold lower VWF propeptide/antigen ratio and demonstrating that BT200 does not increase VWF secretion or release.

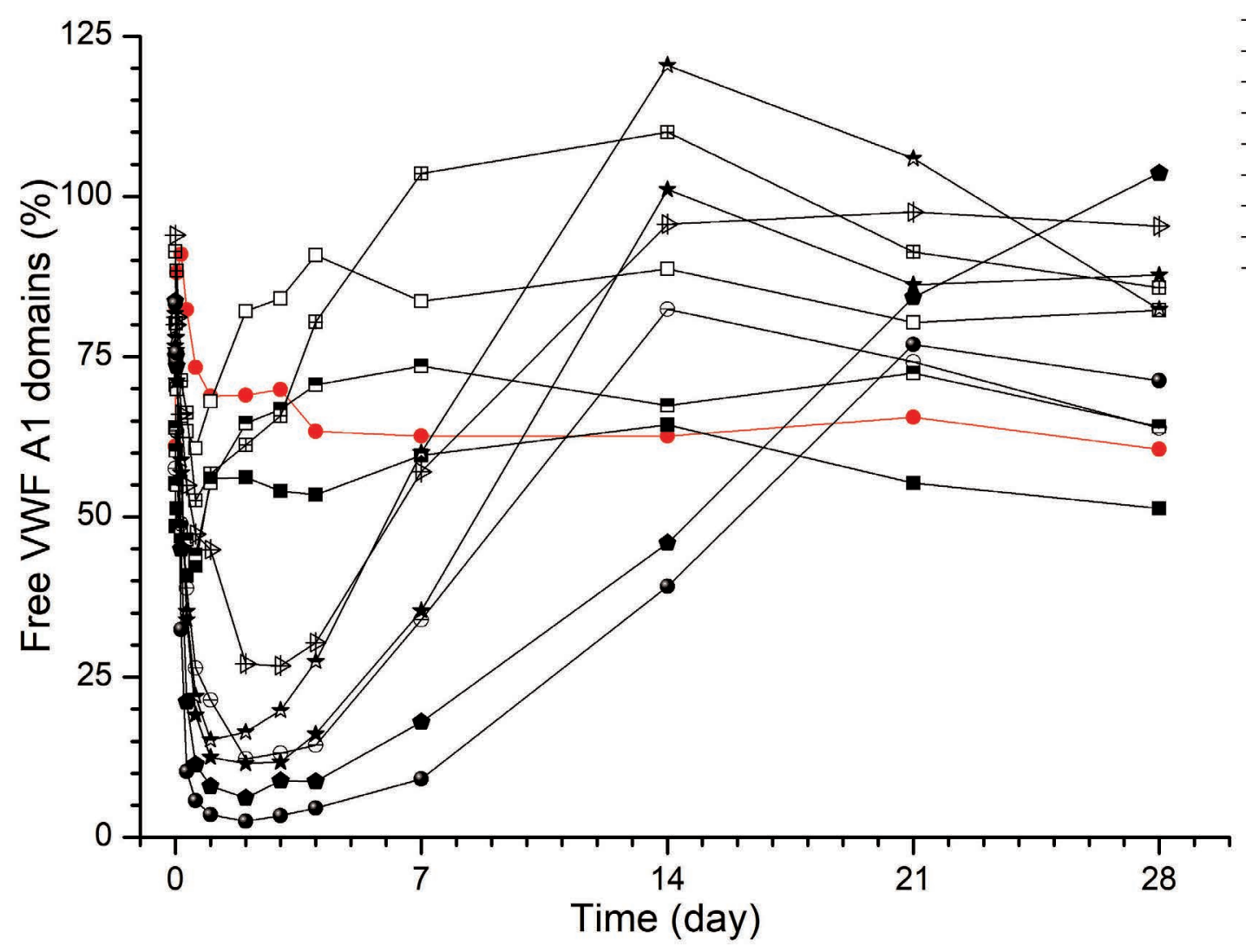

- placebo

$-0.18 \mathrm{mg} \mathrm{sc}$ inj

$-0.6 \mathrm{mg} \mathrm{sc}$ inj

$\square-1.8 \mathrm{mg} \mathrm{sc}$ inj

巴-6.0mg sc inj

๘ $12.0 \mathrm{mg} \mathrm{sc}$ inj

$\pitchfork 18.0 \mathrm{mg} \mathrm{sc} \mathrm{inj}$

- $24.0 \mathrm{mg} \mathrm{sc}$ in

$\star 24.0 \mathrm{mg} \mathrm{sc}$ inf

$-36.0 \mathrm{mg} \mathrm{sc}$ inf

$-48.0 \mathrm{mg} \mathrm{sc}$ inf

Figure 2. Free von Willebrand factor A1-domains (\%) after single doses of BT200, measured by enzyme-linked immunosorbent assay. Data are mean values without error bars for better visibility ( $n=6$ for BT200 groups, $n=20$ for placebo). VWF: von Willebrand factor; sc: subcutaneous; inj: injection; inf: infusion.

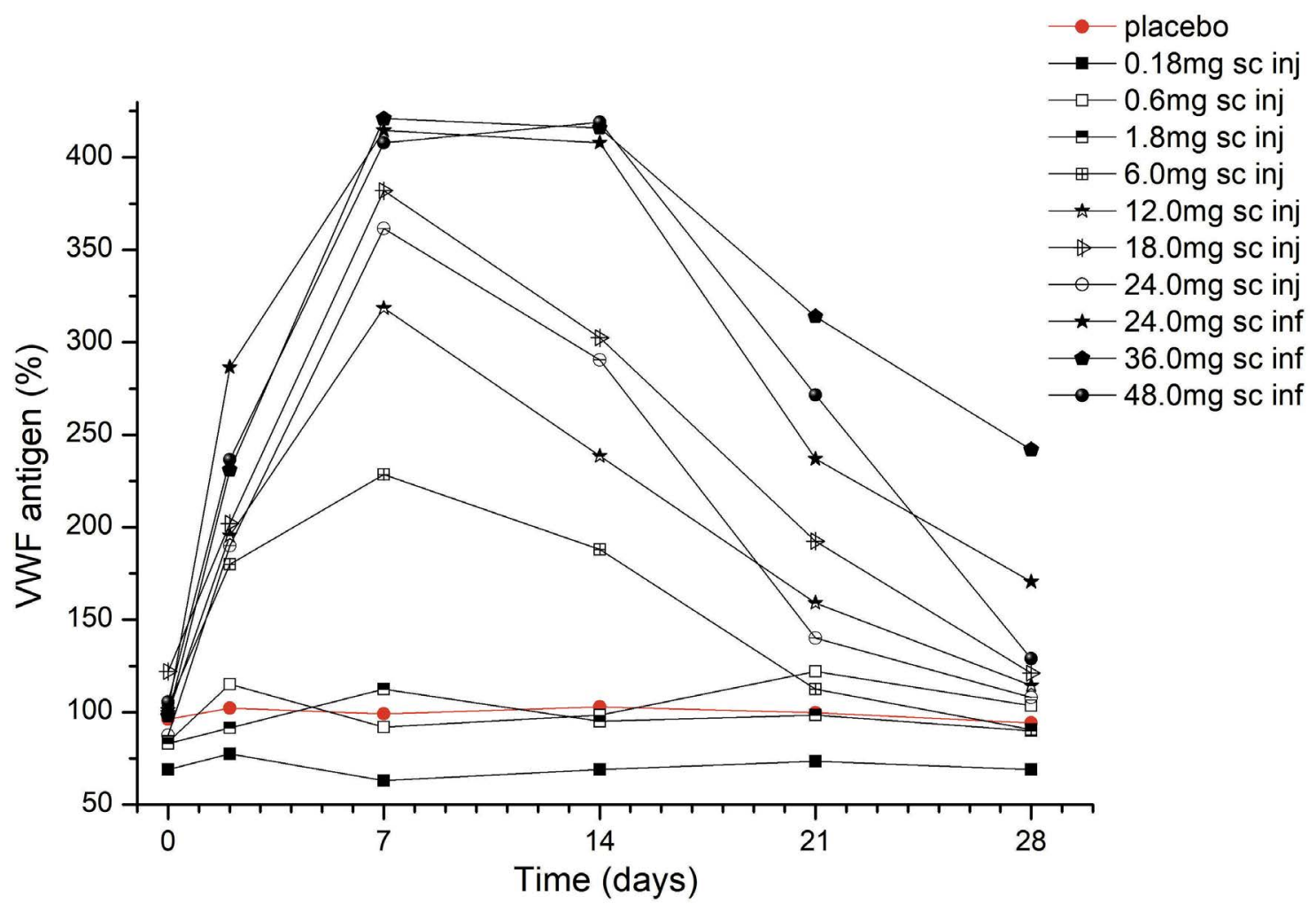

Figure 3. Plasma levels of von Willebrand factor antigen (\%) after single doses of BT200. Data are mean values without error bars for better visibility ( $n=6$ for BT200 groups, $n=20$ for placebo). VWF: von Willebrand factor; sc: subcutaneous; inj: injection; inf: infusion. 
No apparent sex differences were noted in pharmacokinetic or pharmacodynamic values.

\section{Desmopressin challenge}

Eight subjects were included in part C, of whom four (including 1 woman) were re-exposed from part A. All were Caucasian and their mean age was 38 years (SD 13) (Online Supplementary Table S4). Desmopressin did not alter BT200 exposure in any meaningful manner (data not shown). In fact, the responses to BT200 and desmopressin appeared to be additive, with the higher FVIII activity observed following BT200 plus desmopressin infusion taking a proportionally longer time to return to baseline (Figure 6).

\section{Half-life estimation}

To estimate the increase in half-life of endogenous VWF/FVIII the following assumptions were made: (i) 4-fold higher levels of VWF/FVIII will increase the AUC 4-fold; (ii) BT200 does not alter endogenous VWF/FVIII release/production (as evidenced by unchanging VWF propeptide levels); (iii) endogenous VWF/FVIII release/production is constant (i.e., similar to a continuous infusion of VWF/FVIII at a constant dose); and (iv) the volume of distribution of VWF does not change (as BT200 is a large molecule with predominantly intravascular distribution).
From this it can be calculated that: (i) the clearance of VWF/FVIII decreased to $25 \%$ of the baseline value (clearance $=$ dose $[1 \mathrm{x}] / \mathrm{AUC}[4 \mathrm{x}]$ ); and (ii) the half-life of endogenous FVIII increases by $~ 2.77$-fold $\left(\mathrm{t}_{1 / 2}=0.693 /\right.$ clearance) (Figure 4).

\section{Specificity of blocking von Willebrand factor clearance}

One of the main clearance pathways of VWF/VIII complex is macrophage low density lipoprotein receptor-related protein 1 (LRP1). BT200 has been demonstrated to affect VWF clearance and this is probably due to the inhibition of the VWF/VIII-LRP1 clearance pathway ${ }^{23}$ (explained in the Discussion). To exclude a non-specific effect on LRP1, we measured levels of two additional molecules: ADAMTS5 ${ }^{24}$ and connective tissue growth factor ${ }^{25}$ in a subgroup of patients. These molecules are specifically cleared by the LRP1 receptor. Their levels remained unchanged, indicating that the influence of BT200 on blocking VWF clearance is highly specific (data not shown).

\section{Safety}

A list of adverse events, presented according to affected system organ class, is provided in Online Supplementary Table S5. Overall, the tolerability and safety of BT200 were good and similar to those of placebo, with an exception attributable to exaggerated pharmacology: dose-related

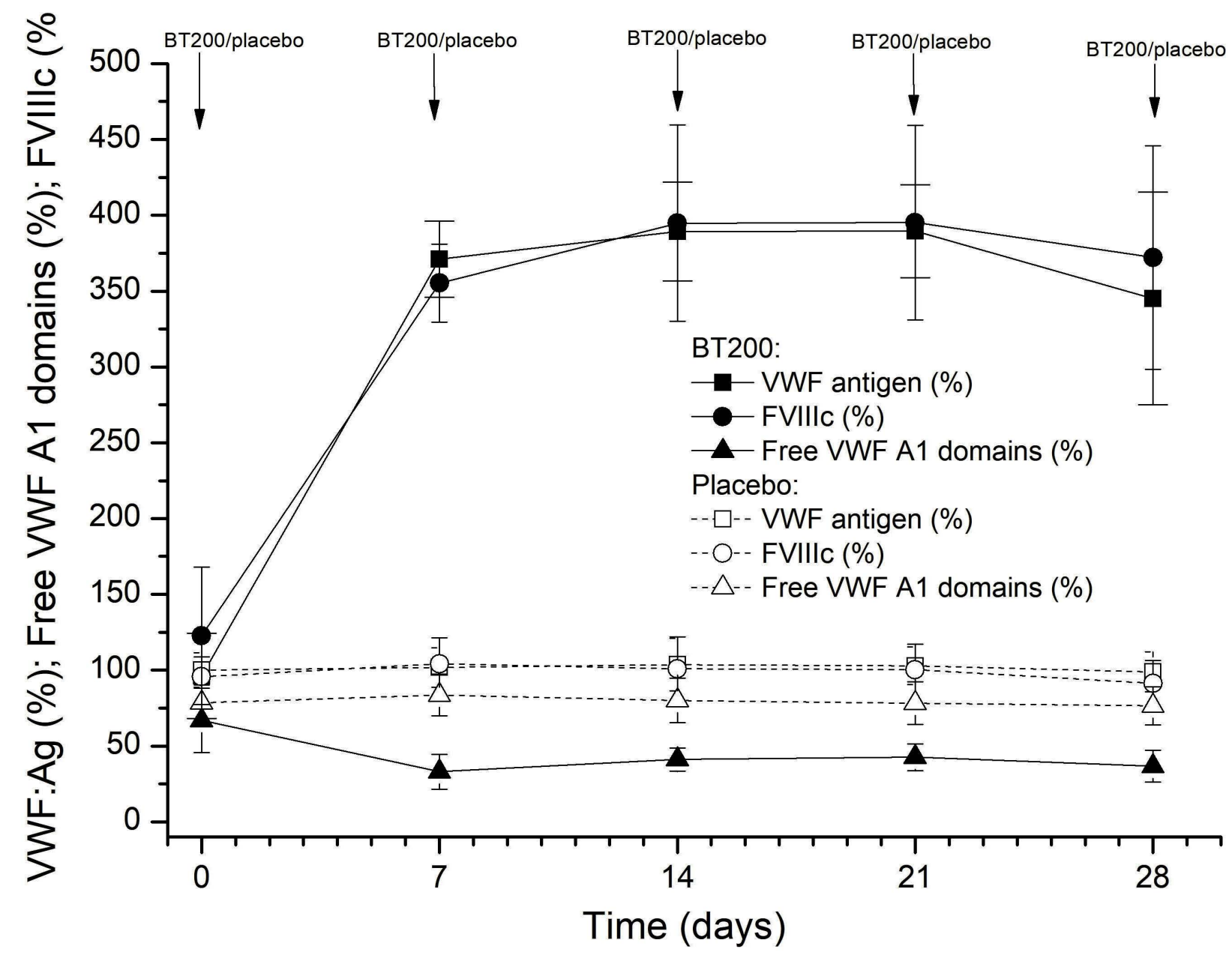

Figure 4. von Willebrand factor antigen levels, free A1-domains and factor VIII activity (\%) after multiple doses of BT200. Subjects received $12 \mathrm{mg}$ BT200 intravenously plus $12 \mathrm{mg}$ subcutaneously on the first day and 12 mg subcutaneously weekly or placebo. Data are presented as mean values with $95 \%$ confidence intervals ( $n=6$ for BT200 groups, $n=20$ for placebo). VWF: von Willebrand factor; Ag: antigen; FVIIIc: factor VIII activity. 
episodes of minor spontaneous bleeding that occurred in the form of epistaxis and gingival bleeding, and minor provoked bleeding in the form of venepuncture-related hematomata. This occurred in one of 24 subjects given 24 $\mathrm{mg}$ BT200, and in 5/18 subjects given a $48 \mathrm{mg}$ single-dose of BT200. There was only one healthy volunteer with thrombocytopenia (he received BT200 intravenously). He had low platelet counts at the start of the trial $\left(142 \times 10^{9} / \mathrm{L}\right.$ decreasing to a minimum of $117 \times 109 / L)$, but these normalized towards the end of the trial. He also experienced a local hematoma. There was no fall in hemoglobin in any participant.

It is of note that one subject developed venous thrombosis and another subject thrombophlebitis at the insertion

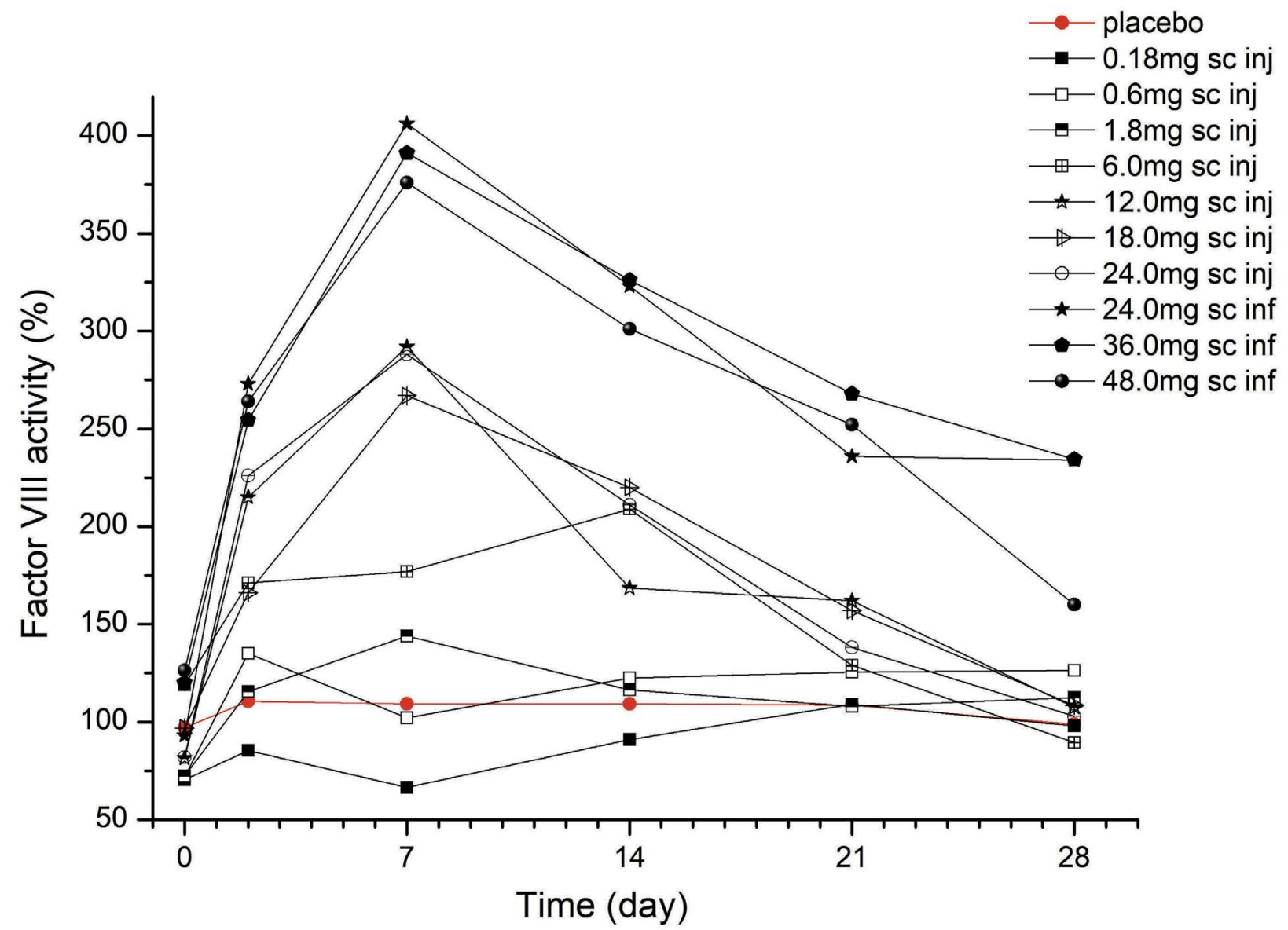

Figure 5. Factor VIII activity levels after single doses of BT200. Data are mean values without error bars for better visibility ( $\mathrm{n}=6$ for BT200 groups, n=20 for placebo). sc: subcutaneous; inj: injection; inf: infusion.

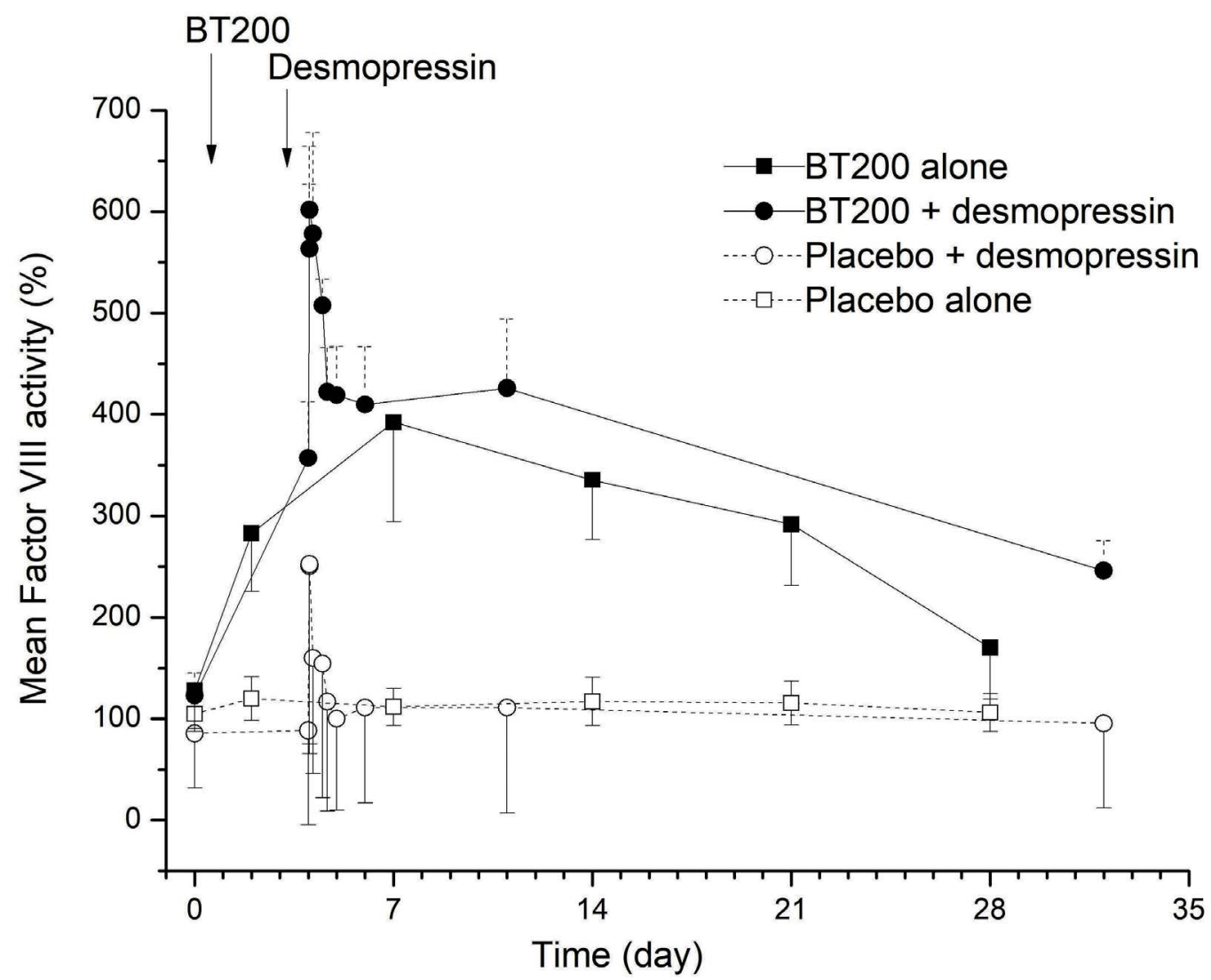

Figure 6. Factor VIII clotting activity (\%) after combined administration of BT200/placebo with desmopressin or BT200/placebo alone. Data are represented as mean values with $95 \%$ confidence interval ( $n=6$ for BT200 groups, $n=20$ for placebo, $n=2$ for placebo+desmopressin). 
site of the venous catheter (median cubital vein). This was diagnosed with color-coded duplex sonography and both events were treated with enoxaparin. One subject received 8000 IE SC once daily, and the other 4000 IE SC once daily. Additionally, one volunteer developed venous thrombosis of the limb (lower left leg) and was treated with enoxaparin 6000 IE SC for 4 days, and then with edoxaban $60 \mathrm{mg}$ once a day for 11 weeks. Furthermore he was prescribed compression stockings. Lastly, one subject developed thrombophlebitis of the cubital vein and a superficial thrombophlebitis which extended into the great saphenous vein. In this subject factor $V$ Leiden, which would predispose him to thrombotic events, was diagnosed. He was treated with enoxaparin 8000 IE SC $2 \times 1$ for 5 days and then with edoxaban $60 \mathrm{mg}$ orally $1 \times 1$. Subjects who experienced these events received a single dose of BT200 $\geq 36$ $\mathrm{mg}$ (3 of 4 subjects and 1 of them also received desmopressin), or repeated weekly doses of $12 \mathrm{mg}$ (in the remaining 1 subject).

D-dimer and prothrombin fragment levels were measured in 28 subjects. Although no significant difference between levels in the placebo and BT200 groups was seen, two out of seven subjects in the placebo arm had elevated Ddimer levels at baseline (0.95 and $1.61 \mu \mathrm{g} / \mathrm{mL})$, and three more placebo-treated subjects showed elevated D-dimer levels in at least one blood sample (0.75, 1.07, 1.43 $0 \mu \mathrm{g} / \mathrm{mL}$ ). Therefore, due to its low specificity, we decided not to continue measuring D-dimer levels. However, Ddimer levels do demonstrate a good negative predictive value for ruling out pulmonary embolism when in the normal range. ${ }^{26}$

Three serious adverse events occurred, all of which were considered to be unrelated to the study drug. One subject on placebo had severe back pain which was treated in hospital, one subject receiving $24 \mathrm{mg}$ suffered a bone fracture 24 days after dosing and underwent surgery, and one subject had an intervertebral disc protrusion 17 days after treatment with $48 \mathrm{mg}$ BT200. She was managed with repeated desmopressin infusions to restore VWF-dependent platelet function before undergoing surgery.

\section{Discussion}

This first-in-human trial examined the tolerability, safety, pharmacokinetics and pharmacodynamic effects of the VWF A1-binding aptamer, BT200. In previous non-human primate studies the median half-life was found to be 3-4 days for BT200 doses ranging from $0.5-10 \mathrm{mg} / \mathrm{kg} .{ }^{21}$ In our healthy volunteers, the estimated half-life ranged from 712 days for BT200 doses approximately $\geq 0.02 \mathrm{mg} / \mathrm{kg}$, which is 2- to 3-fold longer than the dose in monkeys. Single SC doses of $\geq 12 \mathrm{mg}$ BT200 yielded plasma concentrations of $\sim 1 \mu \mathrm{g} / \mathrm{mL}$ in humans which dose-dependently decreased
VWF activity and shear-dependent platelet function by $>50 \%$. This indicates that the concentration-effect relationships seen in recent in vitro studies using human blood $d^{7,27,28}$ are directly applicable to the in vivo clinical pharmacology. Treatment with $\geq 1 \mathrm{mg} / \mathrm{kg}$ BT200 inhibited VWF-dependent platelet function and thrombus formation in non-human primates, ${ }^{21}$ suggesting a possible therapeutic role for BT200 in the secondary prevention of cardio- and cerebrovascular diseases. ${ }^{27}$ Interestingly, as this was not seen in the preliminary monkey studies, BT200 increased VWF antigen levels and FVIII activity up to 4-fold above baseline. As BT200 did not increase VWF propeptide levels, this increase in VWF/FVIII can be explained by decreased clearance of VWF. The mechanism of VWF clearance is complex and involves different receptors, ${ }^{29}$ and VWF clearance dominates FVIII clearance. ${ }^{30}$ While this trial was still ongoing, it was published that pegylation of VWF A1-domains with $40 \mathrm{kDa}$ polyethylene glycol decreases their clearance by the macrophage LRP1. ${ }^{23}$ BT200 binding to the A1-domain of VWF indirectly "pegylates" the A1-domain, and decreased clearance is the likely underlying mechanism of action for the observed increase in VWF/FVIII levels. $X$-ray crystallography demonstrates that BT200 binds to the VWF A1-domain with multiple contacts in the region from R1395 to Q1402. ${ }^{21}$ This region includes a critical binding site on VWF-A1 for LRP1, the primary clearance receptor for the VWF/FVIII complex, i.e., K1408 on VWF A1. ${ }^{31}$ This same region from R1395 to Q1402 on VWF-A1 partially overlaps with that of the corresponding binding site for glycoprotein Ib, providing a biophysical basis for the observed pharmacological competition between BT200 and platelet glycoprotein $\mathrm{Ib} .^{21}$

The FVIII was hemostatically active, which was not only reflected by a shortening of the activated partial thromboplastin time, but also by an increase in the endogenous thrombin potential. While the overall safety and tolerability profiles of BT200 were good and similar to nonclinical safety experience in non-human primates, this heightened hemostatic activity resulted in the occurrence of venous thrombosis and thrombophlebitis at the insertion site of venous catheters in two subjects. Additionally, distal venous thrombosis/thrombophlebitis occurred in two further subjects, one of whom had a medical history of previous thrombosis associated with the factor $V$ Leiden mutation. One may potentially be able to explain the otherwise rare events of thrombosis of the upper limbs as follows. After venous puncture, normal hemostasis induces a localized platelet plug to stop bleeding. Normally, thrombus growth is stopped by endogenous fibrinolysis. However, after the administration of BT200 there is an increase in endogenous thrombin potential due to supra-normal FVIII levels. This leads to the localized plug growing, and it then becomes clinically visible thrombosis. 
The increased procoagulant properties are suboptimal for further development of BT200 for the secondary prevention of arterial diseases, because they would mandate simultaneous anticoagulation to prevent venous thrombosis in an elderly population. The only exception may be rare patients with low FVIII levels, who require secondary prevention of arterial thrombosis with a potent antiplatelet drug, which clearly represents a therapeutic dilemma. ${ }^{32}$

This requires strategic rethinking and pivoting BT200 as a pro-hemostatic agent. From a safety perspective, BT200 caused only a minor mucocutaneous bleeding pattern, with epistaxis seen at high doses ( $\geq 24 \mathrm{mg}$ ). This is consistent with the clinical phenotype of deficiency in VWD and consistent with the exaggerated pharmacology of other VWF inhibitors. ${ }^{15}$ If needed, a rapidly acting, specific, reversal agent has been developed, ${ }^{33}$ and will allow immediate restoration of VWF-dependent hemostasis, for example in the case of trauma or emergency surgery.

The dose- and concentration-response relationship between BT200 and the inhibition of VWF-mediated platelet function, and the increase of FVIII, can, however, be partially separated. The FVIII elevating effect begins at a lower dose ( $6 \mathrm{mg}$ ) while the VWF inhibiting effect does not yet occur ( $\geq 12 \mathrm{mg}$ ). In addition, the plasma levels of free A1domains of VWF appear to stabilize mostly around $40 \%$ of normal values under repeated maintenance doses of 12 $\mathrm{mg}$ due to an increase in circulating VWF mass. It can be anticipated that repeated doses of $\geq 6 \mathrm{mg}$ can be used to elevate VWF/FVIII, without inhibiting primary hemostasis by a relevant degree, and heavier patients or those with high baseline VWF levels may even benefit from higher doses.

Which groups of patients might potentially benefit from BT200? From the estimated 2-to 3-fold increase in FVIII half-life, one would expect a similar increase in half-life of exogenous FVIII in patients with severe hemophilia or type 3 VWD practising prophylactic replacement therapy. Such a half-life prolongation could be seen with regular FVIII products and even extended half-life products, which would be welcome because of the ceiling effect of VWF on the FVIII half-life. This property can be used to prolong the dosing interval, thus permitting treatment once a week rather than every second day. Additionally, dosages could also be individually tailored to obtain higher trough FVIII levels.

Apart from patients with severe hemophilia, BT200 could for the first time provide an opportunity for patients with moderate or mild hemophilia or female carriers with low FVIII levels and associated severe menstrual bleeding to practise prophylaxis. It has previously been shown that even a modest pharmacologically induced increase in plasma VWF levels can favorably affect the pharmacokinetics of FVIII concentrates used in people with severe hemophilia. ${ }^{34}$ Although desmopressin is effective in a majority of such patients, its antidiuretic effects, adverse events, short duration of action and tachyphylaxis make it unsuitable for long-term prophylaxis. ${ }^{34,35}$ However, our data show that combined use of desmopressin with BT200 has an additive effect on VWF and FVIII levels, and together with previous data on ARC1779, it appears that the effect of desmopressin could be prolonged by BT200.18 This could also allow lower doses or intranasal desmopressin to be used at intervals, which would minimize antidiuretic effects. However, based on the estimated 2.8fold prolongation in half-life, we would expect that a 2to 3-fold increase in endogenous FVIII levels can be achieved by BT200 alone. Finally, certain patients with other subtypes of VWD including, but not necessarily limited to, high clearance variants of type $1 C \mathrm{VWD}$, or type 2B VWD may benefit from the use of BT200. In type 2B VWD, there are gain-of-function mutations often in the $A 1$ domain, which increase the affinity of VWF for Gplb leading to spontaneous VWF attachment to platelets. This often results in a loss of large multimers, ${ }^{36}$ and low VWF plasma levels due to high clearance, as indicated by the increased VWFpp:VWF ratios in type $2 \mathrm{~B}$ patients. ${ }^{37}$ Similarly, murine variants carrying type $2 \mathrm{~B}$ mutations result in a shortened VWF half-life, as well as increased clearance of platelets coated with such mutants. ${ }^{38}$ We previously provided proof of the concept that blocking the A1-domain of VWF by infusion of ARC1779 was able to increase VWF/FVIII levels, to normalize multimer patterns and to improve the associated thrombocytopenia in patients suffering from type 2B VWD. ${ }^{18,19}$ As BT200 increases VWF/FVIII levels by decreasing the clearance of these proteins in healthy individuals, it could potentially increase their levels in all VWD patients, but particularly in those with high clearance variants (VWD type 1C). For example, patients with type Vicenza VWD may have a VWF half-life 10fold shorter than normal, as well as FVIII deficiency. ${ }^{39}$ It is conceivable that BT200 may be beneficial as it counteracts the increased clearance.

This study does have some limitations. We were only able to include women of non-childbearing potential due to a demand from the regulatory agency. Therefore, only 11 women participated in the trial. Similarly, ethnic diversity was limited. However, as BT200 is a large molecule, which predominantly distributes to the intravascular compartment without being metabolized, no relevant differences are expected between sexes or people of different ethnicity. As the bleeding burden in females with hemophilia $A$ has long been neglected, which has only recently resulted in a new nomenclature, ${ }^{40}$ future trials will have to include a larger proportion of women.

In summary, BT200 is a first-in-class molecule with a novel mechanism of action representing a new therapeutic strategy to break the ceiling effect that VWF imposes on 
FVIII half-life. This prolongs the half-life of VWF/FVIII, which could allow regular prophylaxis in patients with non-severe hemophilia A, as well as allowing VWD patients to increase their VWF/FVIII levels.

\section{Disclosures}

$J C G$ and $S Z$ are founders of, and BJ and BM are consultants for Guardian Therapeutics. The other authors have no relevant conflicts of interest to declare.

\section{Contributions}

$K D K$ and $A B$ performed the pharmacokinetic and part of the pharmacodynamic analyses. JG, GGe, GGa, CS, CF and UD (the principal investigator) were responsible for conducting the trial. BJ and JCG designed the trial, wrote the protocol and $S Z$ developed the analytical methods. PJ-S and $P Q$ were responsible for laboratory analyses and for quality checking methods. MB performed the pharmokinetic/pharmodynamic modeling and wrote the pharmokinetic/pharmodynamic report. All authors contributed to both writing and critically reviewing the manuscript.

\section{Acknowledgments}

This trial was sponsored by Guardian Therapeutics. We would like to thank the following staff members for their outstanding logistic support and help: Christa Drucker, Karin Petroczi, Sabine Schranz, RN and Sarah Ely, RN, BA, PgDip who also edited the manuscript.

\section{Data-sharing statement}

Upon a justified request, the principal investigator will grant access to the primary clinical trial data.

\section{References}

1. Lollar P. The association of factor VIII with von Willebrand factor. Mayo Clin Proc. 1991;66(5):524-534.

2. Ruggeri ZM, Mendolicchio GL. Interaction of von Willebrand factor with platelets and the vessel wall. Hamostaseologie. 2015;35(3):211-224.

3. Kiouptsi K, Reinhardt C. Physiological roles of the von Willebrand factor-factor VIII interaction. Subcell Biochem. 2020;94:437-464.

4. Lavin M, O'Donnell JS. How I treat low von Willebrand factor levels. Blood. 2019;133(8):795-804.

5. Lillicrap D. von Willebrand disease: advances in pathogenetic understanding, diagnosis, and therapy. Blood. 2013;122(23):3735-3740.

6. Tomeo F, Mariz S, Brunetta AL, Stoyanova-Beninska V, Penttila K, Magrelli A. Haemophilia, state of the art and new therapeutic opportunities, a regulatory perspective. Br J Clin Pharmacol. 2021;87(11):4183-4196.

7. Kovacevic KD, Jilma B, Zhu S, et al. von Willebrand factor predicts mortality in ACS patients treated with potent $\mathrm{P} 2 \mathrm{Y} 12$ antagonists and is inhibited by aptamer BT200 ex vivo. Thromb Haemost. 2020;120(9):1282-1290.

8. Spiel AO, Mayr FB, Ladani N, et al. The aptamer ARC1779 is a potent and specific inhibitor of von Willebrand factor mediated ex vivo platelet function in acute myocardial infarction. Platelets. 2009;20(5):334-340.

9. Buchtele N, Schwameis M, Gilbert JC, Schorgenhofer C, Jilma B. Targeting von Willebrand factor in ischaemic stroke: focus on clinical evidence. Thromb Haemost. 2018;118(6):959-978.

10. Markus HS, McCollum C, Imray C, Goulder MA, Gilbert J, King A. The von Willebrand inhibitor ARC1779 reduces cerebral embolization after carotid endarterectomy: a randomized trial. Stroke. 2011;42(8):2149-2153.

11. Jilma-Stohlawetz P, Gilbert JC, Gorczyca ME, Knobl P, Jilma B. A dose ranging phase $\mathrm{I} / \mathrm{II}$ trial of the von Willebrand factor inhibiting aptamer ARC1779 in patients with congenital thrombotic thrombocytopenic purpura. Thromb Haemost. 2011;106(3):539-547.

12. Lammle B, Kremer Hovinga JA, Alberio L. Thrombotic thrombocytopenic purpura. J Thromb Haemost. 2005;3(8):1663-1675.
13. Cataland SR, Peyvandi F, Mannucci PM, et al. Initial experience from a double-blind, placebo-controlled, clinical outcome study of ARC1779 in patients with thrombotic thrombocytopenic purpura. Am J Hematol. 2012;87(4):430-432.

14. Jilma-Stohlawetz P, Gorczyca ME, Jilma B, Siller-Matula J, Gilbert JC, Knobl P. Inhibition of von Willebrand factor by ARC1779 in patients with acute thrombotic thrombocytopenic purpura. Thromb Haemost. 2011;105(3):545-552.

15. Knoebl P, Cataland S, Peyvandi F, et al. Efficacy and safety of open-label caplacizumab in patients with exacerbations of acquired thrombotic thrombocytopenic purpura in the HERCULES study. J Thromb Haemost. 2020;18(2):479-484.

16. Peyvandi F, Scully M, Kremer Hovinga JA, et al. Caplacizumab reduces the frequency of major thromboembolic events, exacerbations and death in patients with acquired thrombotic thrombocytopenic purpura. J Thromb Haemost. 2017;15(7):1448-1452.

17. Scully M, Cataland SR, Peyvandi F, et al. Caplacizumab treatment for acquired thrombotic thrombocytopenic purpura. N Engl J Med. 2019;380(4):335-346.

18. Jilma B, Paulinska P, Jilma-Stohlawetz P, Gilbert JC, Hutabarat $R$, Knobl P. A randomised pilot trial of the anti-von Willebrand factor aptamer ARC1779 in patients with type $2 \mathrm{~b}$ von Willebrand disease. Thromb Haemost. 2010;104(3):563-570.

19. Jilma-Stohlawetz $P$, Knobl P, Gilbert JC, Jilma B. The anti-von Willebrand factor aptamer ARC1779 increases von Willebrand factor levels and platelet counts in patients with type $2 \mathrm{~B}$ von Willebrand disease. Thromb Haemost. 2012;108(2):284-290.

20. Jilma-Stohlawetz P, Gorczyca ME, Jilma B, Siller-Matula J, Gilbert JC, Knobl P. Inhibition of von Willebrand factor by ARC1779 in patients with acute thrombotic thrombocytopenic purpura. Thromb Haemost. 2011;105(3):545-552.

21. Zhu S, Gilbert JC, Hatala P, et al. The development and characterization of a long acting anti-thrombotic von Willebrand factor (VWF) aptamer. J Thromb Haemost. 2020;18(5):1113-1123.

22. Kovacevic KD, Gilbert JC, Jilma B. Pharmacokinetics, pharmacodynamics and safety of aptamers. Adv Drug Deliv Rev. 2018;134:36-50.

23. Fazavana J, Brophy TM, Chion A, et al. Investigating the clearance of VWF A-domains using site-directed PEGylation and 
novel N-linked glycosylation. J Thromb Haemost. 2020;18(6):1278-1290.

24. Yamamoto K, Troeberg L, Scilabra SD, et al. LRP-1-mediated endocytosis regulates extracellular activity of ADAMTS- 5 in articular cartilage. FASEB J. 2013;27(2):511-521.

25. Gerritsen KG, Bovenschen N, Nguyen TQ, et al. Rapid hepatic clearance of full length CCN-2/CTGF: a putative role for LRP1mediated endocytosis. J Cell Commun Signal. 2016;10(4):295-303.

26. Kearon C, de Wit K, Parpia S, et al. Diagnosis of pulmonary embolism with $d$-dimer adjusted to clinical probability. N Engl $J$ Med. 2019;381(22):2125-2134.

27. Kovacevic KD, Greisenegger S, Langer A, et al. The aptamer BT200 blocks von Willebrand factor and platelet function in blood of stroke patients. Sci Rep. 2021;11(1):3092-3101.

28. Kovacevic KD, Buchtele N, Schoergenhofer C, et al. The aptamer BT200 effectively inhibits von Willebrand factor (VWF) dependent platelet function after stimulated VWF release by desmopressin or endotoxin. Sci Rep. 2020;10(1):11180.

29. O'Sullivan JM, Ward S, Lavin M, O'Donnell JS. von Willebrand factor clearance - biological mechanisms and clinical significance. Br J Haematol 2018;183(2):185-195.

30. Pipe SW, Montgomery RR, Pratt KP, Lenting PJ, Lillicrap D. Life in the shadow of a dominant partner: the FVIII-VWF association and its clinical implications for hemophilia A. Blood. 2016;128(16):2007-2016.

31. Chion A, Aguila S, Fazavana J, et al. VWFA1 interacts with scavenger receptor LRP1 via lysine 1408. Res Pract Thromb Haemost. 2019;3(S1):1-228.

32. Martin K, Key NS. How I treat patients with inherited bleeding disorders who need anticoagulant therapy. Blood. 2016;128(2):178-184.

33. Zhu S, Gilbert JC, Liang Z, et al. Potent and rapid reversal of the von Willebrand factor inhibitor aptamer BT200. J Thromb Haemost. 2020;18(7):1695-1704.

34. Deitcher SR, Tuller J, Johnson JA. Intranasal DDAVP induced increases in plasma von Willebrand factor alter the pharmacokinetics of high-purity factor VIII concentrates in severe haemophilia A patients. Haemophilia. 1999;5(2):88-95.

35. Lethagen S. Desmopressin in mild hemophilia A: indications, limitations, efficacy, and safety. Semin Thromb Hemost. 2003;29(1):101-106.

36. Casonato A, Daidone V, Galletta E, Bertomoro A. Type 2B von Willebrand disease with or without large multimers: a distinction of the two sides of the disorder is long overdue. PLoS One. 2017;12(6):e0179566.

37. Casonato A, Gallinaro L, Cattini MG, et al. Reduced survival of type $2 B$ von Willebrand factor, irrespective of large multimer representation or thrombocytopenia. Haematologica. 2010;95(8):1366-1372.

38. Casari C, Lenting PJ, Wohner N, Christophe OD, Denis CV. Clearance of von Willebrand factor. J Thromb Haemost. 2013;11(Suppl 1):202-211.

39. Casonato A, Pontara E, Sartorello F, et al. Identifying type Vicenza von Willebrand disease. J Lab Clin Med. 2006;147(2):96-102.

40. van Galen KPM, d'Oiron R, James P, et al. A new hemophilia carrier nomenclature to define hemophilia in women and girls: communication from the SSC of the ISTH. J Thromb Haemost. 2021;19(8):1883-1887. 